\title{
A Univariate Analysis of Unemployment and Inflation in Italy: A Fractionally Integrated Approach*
}

\author{
Luis A. Gil-Alana**
}

\begin{abstract}
In this article we examine the behaviour of unemployment and inflation in Italy (1970-1994) by means of fractionally integrated techniques. Using a version of the tests of Robinson (1994a) that permits us to test $I(d)$ statistical models, the results show that both variables are $I(d)$ with $d$ smaller than 1 , thus implying mean reverting behaviour. This order of integration substantially varies depending on how we specify the $I(0)$ disturbances, though in general, it oscillates around 0.80 for unemployment and 0.60 for inflation, suggesting that unemployment is more persistent than inflation. Splitting the sample in 1980, the degree of persistence seems higher for the second subperiod in both variables.
\end{abstract}

Key Words: Unemployment; Inflation; Fractional integration .

JEL Code: C22 .

* The author gratefully acknowledges the comments of two anonymous referees. Financial support from the Government of Navarra, through the Grant "Ayudas de Formacin $y$ de Investigacin y Desarrollo", Spain, is also acknowledged.

** Universidad de Navarra, Facultad de Ciencias Economicas, Edificio Biblioteca, Entrada Este, E-31080 Pamplona, SPAIN, Phone: 0034948425 625, Fax: 0034948425 626, Email: alana@unav.es

Brazilian Review of Econometrics Rio de Janeiro v.23, nํㅜ 2, pp.227-254 Nov.2003 
A Univariate Analysis of Unemployment and Inflation in Italy

\section{Resumo}

Este artigo analisa o comportamento do desemprego e da inflação na Itália (1970-1994) através de técnicas de integração fracionária. Utilizando uma versão dos testes de Robinson (1994a), que nos permite testar os modelos estatísticos $I(d)$, chegamos ao resultado de que ambas as variáveis são $I(d)$ com $d$ menor que 1 , implicando assim um processo de reversão à média. Esta ordem de integração varia muito, dependendo de como especificamos as perturbações $I(0)$, embora, em geral, ela oscile em torno de 0.80 para o desemprego e 0.60 para a inflação, sugerindo que o desemprego é mais persistente que a inflação. Dividindo a amostra em 1980, o grau de persistência parece mais alto para o segundo subperíodo em ambas as variáveis.

\section{Introduction.}

In this article we are concerned with the statistical modelling of unemployment and inflation in Italy. However, instead of using classical approaches based on $I(0)$, allow for a fractional degree of integration. In doing so, we permit a much greater degree of flexibility in the dynamic behaviour of the series compared with the classical integer differencing models.

For the purpose of the present paper, we define an $I(0)$ process $\left\{u_{t}, t=0, \pm 1\right.$,

density function that is positive and finite at the zero frequency. In this context, we say that $\left\{x_{t}, t=0, \pm 1, \ldots\right\}$ is $I(d)$ if:

$$
\begin{array}{rlrl}
(1-L)^{d} x_{t} & =u_{t}, & t & =1,2, \\
x_{t} & =0, & t \leq 0,{ }^{1}
\end{array}
$$

where the polynomial in (1) can be expressed in terms of its Binomial expansion such that for all real $d$,

${ }^{1}$ Eq. (2) is a standard assumption to be made in fractionally integrated models. (See, e.g., Gil-Alana and Robinson, 1997). 


$$
(1-L)^{\boldsymbol{d}}=\sum_{j=1}^{\infty} \frac{\Gamma(d+1)(-L)^{j}}{\Gamma(d-j+1) \Gamma(j+1)}=1-d L+\frac{d(d-1)}{2}-\ldots
$$

where $\Gamma(x)$ means the gamma function. The macroeconomic literature stresses the cases of $d=0$ and $d=1$. In particular, unemployment and inflation are two variables that have been generally assumed to be $I(1)$ and thus, inference based on cointegration has been developed to explain the dynamic behaviour of the series (e.g., Barsky, 1987; Rose, 1988; Ball and Cecchetti, 1990; Carruth et al., 1998; Marcelino and Mizon, 2001; etc.). However, as it was shown by Adenstedt, 1974 and Taqqu, 1975, the number of differences required to achieve $I(0)$ stationarity may not necessarily be an integer number. If $d>0$ in (1), $x_{t}$ is said to be a long memory process because of the strong association between observations widely separated in time. If $d<0.5, x_{t}$ is still stationary, but its lag- $j$ autocovariance $\gamma_{j}$ decreases very slowly, like the power law $j^{2 \boldsymbol{d}-1}$ as $j \rightarrow \infty$ and so the $\gamma_{j}$ are non-summable. If $d \in(0.5,1), x_{t}$ is no longer covariance stationary but still it is mean reverting, i.e., with the effects of the shocks dying away in the long run. This type of model was introduced by Granger and Joyeux (1980), Granger $(1980,1981)$ and Hosking (1981) and they were theoretically justified in terms of aggregation by Robinson (1978), Granger (1980) and more recently in terms of the duration of shocks by Parke (1999)2 .

In this article we model the univariate behaviour of the Italian unemployment and inflation rates by means of using fractionally integrated techniques. We use the tests of Robinson (1994a), which include, as particular cases, the tests of $I(0), I(1)$ or $I(2)$ specifications. These tests are briefly described in Section 2. In Section 3,

\footnotetext{
${ }^{2}$ Similarly, Croczek-Georges and Mandelbrot (1995), Taqqu et al. (1997), Chambers (1998) and Lippi and Zaffaroni (1999) also use aggregation to motivate long memory processes.
} 
they are applied to quarterly data of the unemployment and inflation rates in Italy. A semiparametric procedure is also implemented in this section. Finally, Section 4 contains some concluding comments.

\section{The tests of Robinson (1994a).}

Robinson (1994a) proposes a very general procedure for testing unit roots and other nonstationary (and stationary) hypotheses in raw time series. However, unlike most commonly used unit root tests, which are embedded in autoregressive (AR) alternatives, (e.g. Dickey and Fuller, 1979; Phillips and Perron, 1988; Kwiatkowski et al., 1992; etc.), the tests of Robinson (1994) are nested in a fractionally integrated model.

Following Bhargava (1986), Schmidt and Phillips (1992) and others on parameterization of unit root models, Robinson (1994a) considers the regression model,

$$
y_{t}=\beta^{\prime} z_{t}+x_{t}, \quad t=1,2, \ldots,
$$

where $y_{t}$ is the time series we observe; $\beta$ is a $(k \times 1)$ vector of unknown parameters; $z_{t}$ is a $(k \times 1)$ vector of deterministic regressors, and the regression errors, $x_{t}$, are of form as in (1) with $I(0) u_{t}$. He proposed a Lagrange Multiplier (LM) test of the null hypothesis:

$$
H_{o}: d=d_{o}
$$

in (1) - (3) for any given real value $d_{o}$. Specifically, the test statistic is given by:

$$
\hat{r}=\left(\frac{T}{\hat{A}}\right)^{1 / 2} \frac{\hat{a}}{\hat{\sigma}^{2}},
$$


where $T$ is the sample size and

$$
\begin{gathered}
\hat{a}=\frac{-2 \pi}{T} \sum_{j=1}^{T-1} \psi\left(\lambda_{j}\right) g\left(\lambda_{j} ; \hat{\tau}\right)^{-1} I\left(\lambda_{j}\right) \\
\hat{\sigma}^{2}=\sigma^{2}(\hat{\tau})=\frac{2 \pi}{T} \sum_{j=1}^{T-1} g\left(\lambda_{j} ; \hat{\tau}\right)^{-1} I\left(\lambda_{j}\right) ; \\
\hat{A}=\frac{2}{T}\left(\sum_{j=1}^{T-1} \psi\left(\lambda_{j}\right)^{2}-\sum_{j=1}^{T-1} \psi\left(\lambda_{j}\right) \hat{\varepsilon}\left(\lambda_{j}\right)^{\prime}\right. \\
\left.\times\left(\sum_{j=1}^{T-1} \hat{\varepsilon}\left(\lambda_{j}\right) \hat{\varepsilon}\left(\lambda_{j}\right)^{\prime}\right)^{-1} \times \sum_{j=1}^{T-1} \hat{\varepsilon}\left(\lambda_{j}\right) \psi\left(\lambda_{j}\right)\right)
\end{gathered}
$$

$\psi\left(\lambda_{j}\right)=\log \left|2 \sin \frac{\lambda_{j}}{2}\right| ; \quad \hat{\varepsilon}\left(\lambda_{j}\right)=\frac{\partial}{\partial \tau} \log g\left(\lambda_{j} ; \hat{\tau}\right) ; \quad \lambda_{j}=\frac{2 \pi j}{T} ;$

$\hat{\tau}=\arg \min \sigma^{2}(\tau)$.

$I\left(\lambda_{j}\right)$ is the periodogram of $\hat{u}_{t}$ :

$$
\begin{aligned}
& \hat{u}_{t}=(1-L)^{d_{o}} y_{t}-\hat{\beta}^{\prime} w_{t}, \quad w_{t}=(1-L)^{d_{o}} z_{t} \\
& \hat{\beta}=\left(\sum_{t=1}^{T} w_{t} w_{t}^{\prime}\right)^{-1} \sum_{t=1}^{T} w_{t}(1-L)^{d_{o}} y_{t}
\end{aligned}
$$

and the function $g$ above is a known function coming from the spectral density function of $u_{t}$,

$$
f(\lambda ; \tau)=\frac{\sigma^{2}}{2 \pi} g(\lambda ; \tau), \quad-\pi<\lambda \leq \pi .
$$

Note that these tests are purely parametric and therefore, they require specific modelling assumptions to be made regarding the 
short memory specification of $u_{t}$. Thus, if $u_{t}$ is a white noise, $g \equiv 1$, and if $u_{t}$ is an AR process of form $\phi(L) u_{t}=\varepsilon_{t}, g=\left|\phi\left(e^{i \lambda}\right)\right|^{-2}$, with $\sigma^{2}=V\left(\varepsilon_{t}\right)$, so that the AR coefficients are function of $\tau$.

Based on (4), Robinson (1994a) established that under certain regularity conditions ${ }^{3}$,

$$
\hat{r} \rightarrow_{\boldsymbol{\alpha}} N(0,1) \quad \text { as } \quad T \rightarrow \infty .
$$

In view of (7), we are in a classical large-sample testing situation for reasons described by Robinson (1994a) who also showed that the tests are efficient in the Pitman sense against local departures from the null hypothesis. Furthermore, this standard distribution holds independently of the regressors used in $z_{t}$ in (3) and the type of $I(0)$ disturbances $u_{t}$ in (1). Thus, an approximate one-sided test of $H_{o}$ (4) against the alternative $H_{a}: d>d_{o}\left(d<d_{o}\right)$ rejects $H_{o}$ (4) if $\hat{r}>z_{\alpha}\left(\hat{r}<z_{\alpha}\right)$, where the probability that a standard normal variate exceeds $z_{\alpha}$ is $\alpha$. This version of the tests of Robinson (1994a) was used in empirical applications in Gil-Alana and Robinson (1997) and Gil-Alana (2000a), and other versions of Robinson's (1994a) tests based on seasonal (quarterly and monthly) and cyclical data are respectively Gil-Alana and Robinson (2001) and Gil-Alana (1999, 2001).

\section{Testing the order of integration in the Italian unemploy- ment and inflation rates.}

The time series analysed in this section correspond to the quarterly seasonally adjusted data for the time period 1970.1 - 1994.4. (Seasonally unadjusted data were not available over this period). Unemployment is measured as the log of the percentage unemployment rate while inflation is taken as the first differences of the log of

\footnotetext{
${ }^{3}$ These conditions are very mild, regarding technical assumptions to be satisfied by $\psi\left(\lambda_{j}\right)$.
} 
the CPI. These data were obtained from the JAE data archive and were used by Marcelino and Mizon (2001) in an article about the relationship between real wages, inflation, unemployment and output per capita in Italy. In that paper they assume that unemployment and inflation are both I(1) even when splitting the data in $1980^{4}$.

Figure 1 displays plots of the original series with their corresponding correlograms and periodograms. Starting with unemployment, we see that the values started rising in the late 70s, and there are two abrupt changes, one corresponding to 1973.2 (up to 8\%) just prior to the first oil price crisis and the other one in 1993.2, probably due to a change in the questionnaire used to collect the data. The nonstationary nature of this series becomes apparent when we look at the correlogram (with values decaying very slowly) and also through the periodogram (with a large peak around the smallest frequency). Similarly for inflation, the dominant path rises strongly from 1972 to 1980 whereupon it falls to 1986 , and then remains constant to the end of the sample. Again here, the correlogram and the periodogram seem to indicate that inflation is nonstationary.

Figure 2 contains similar plots but based on the first differenced data. The most noticeable thing observed here is the significance of the autocorrelation values at some lags relatively far away from zero, which may be an indication that the original series may be fractionally integrated. This is corroborated by the periodograms observing values close to zero at the zero frequency, which could suggest that the series are now overdifferenced.

\footnotetext{
${ }^{4}$ Some authors argue that as unemployment rate is a bounded variable it may lead to problems when testing nonstationary hypotheses. (See, Wallis, 1987). In that respect, the logistic transformation of unemployment was also examined and the results were practically the same as those reported here.
} 
A Univariate Analysis of Unemployment and Inflation in Italy

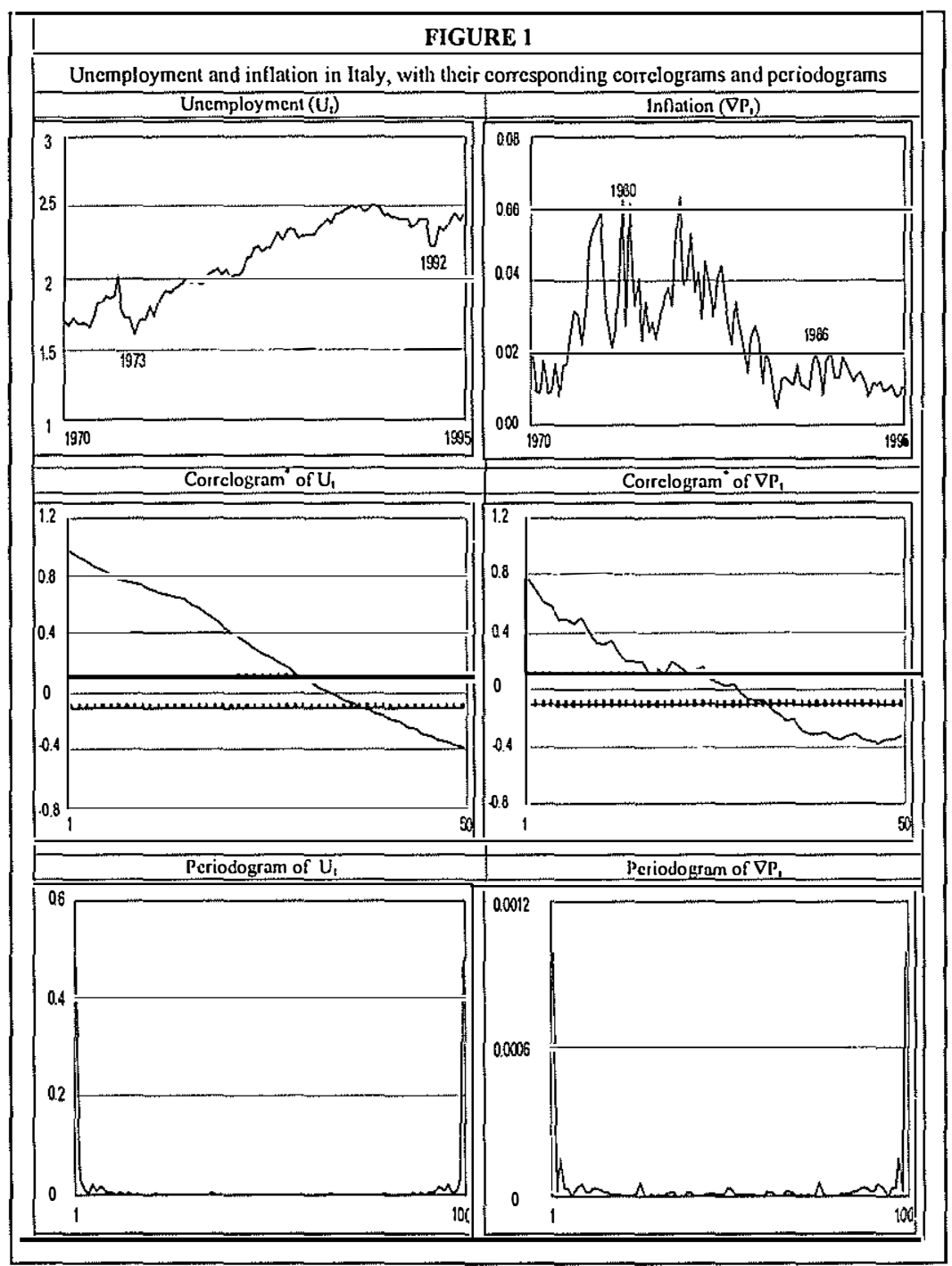

*: The large sample standard error under the null hypothesis of no autocorrelation is $1 / \sqrt{T}$ or roughly 0.10 for series of length considered here. 
Luis A. Gil-Alana

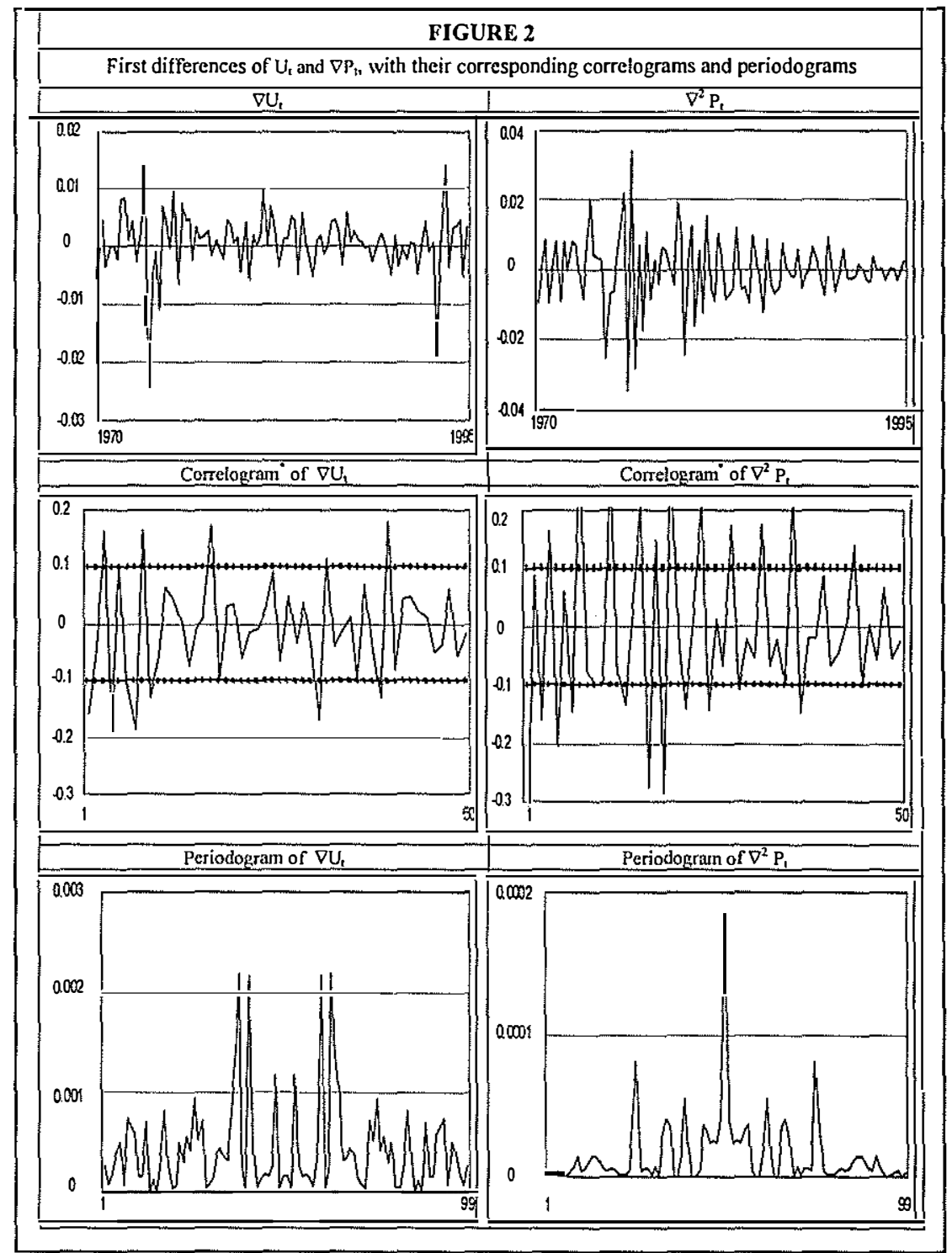

*: The large sample standard error under the null hypothesis of no autocorrelation is $1 / \sqrt{T}$ or roughly 0.10 for series of length considered here.

Brazilian Review of Econometrics 23 (2) November 2003 
A Univariate Analysis of Unemployment and Inflation in Italy

Denoting any of the series $y_{t}$, we employ throughout the model (1) - (3) with $z_{t}=(1, t)^{\prime}, t \geq 1, z_{t}=(0,0)^{\prime}$ otherwise, so under the null hypothesis (4):

$$
\begin{array}{cc}
y_{t}=\beta_{1}+\beta_{2} t+x_{t}, & t=1,2, \ldots \\
(1-L)^{d} x_{t}=u_{t}, & t=1,2, \ldots .
\end{array}
$$

We treat separately the cases $\beta_{1}=\beta_{2}=0$ a priori, $\beta_{1}$ unknown and $\beta_{2}=0$ a priori, and $\left(\beta_{1}, \beta_{2}\right)$ unknown, that is, studying the cases of no regressors, an intercept, and an intercept and a linear time trend respectively, and model the $I(0)$ disturbances $u_{t}$ to be both white noise and to have parametric autocorrelation.

We start with the assumption that $u_{t}$ in (9) is a white noise. Thus, when $d=1$, for example, the differences $(1-L) y_{t}$ behave, for $t>1$, like a random walk when $\beta_{2}=0$, and a random walk with drift when $\beta_{2} \neq 0$. However, we report test statistics not merely for the null hypothesis $d_{o}=1$ in (4) but for $d_{o}=0.50$, (0.10), 1.50, thus including also a test for stationarity $\left(d_{o}=0.50\right)$ and other fractionally integrated possibilities.

The test statistic reported in Table 1 is the one-sided one given by $\hat{r}$ in (5), so that its significantly positive values are consistent with alternatives of form: $d>d_{o}$, whereas significantly negative ones are consistent with $d<d_{o}$,

A notable feature in the upper part of Table 1 (in which $u_{t}$ is a white noise) is the fact that the test statistic monotonically decreases with $d_{o}$.

discussion and the fact that they are one-sided statistics.

\footnotetext{
${ }^{5}$ We use standard normal critical values. Finite sample critical values of this version of the tests of Robinson (1994a) were obtained in Gil-Alana (2000b). However, the conclusions obtained in this application are not affected by this.
} 
Starting with unemployment, we observe that if we do not include regressors in (8), $H_{o}$ (4) cannot be rejected in case of the unit root (i.e., $d=1$ ), although we also observe non-rejections if $d=0.90$ or 1.10. However, including an intercept or an intercept and a linear time trend, the unit root null hypothesis is rejected in favour of smaller orders of integration and the non-rejection values take place when $d=0.80$ and 0.90 . If we look now at the results for inflation, we observe that the values where the null hypothesis cannot be rejected are much smaller, ranging between 0.50 and 0.70 and thus implying nonstationarity but mean reverting behaviour.

The significance of the above results, however, may be in large part due to the fact that we do not take into account the possibility of $I(0)$ autocorrelation in $u_{t}$. Thus, we also performed the tests based on $A R(1)$ and $A R(2)$ disturbances. Starting with unemployment, we observe a lack of monotonicity in the value of the test statistic with respect to $d_{o}$. This lack of monotonicity may be due to model misspecification. Frequently, misspecification inflates both numerator and denominator of $\hat{r}$ to varying degrees, and thus affects $\hat{r}$ in a complicated way. Computing $\hat{r}$ for a range of values of $d_{o}$ is thus useful in revealing possible misspecification, although monotonicity is by no means necessarily strong evidence of correct specification. Looking at the results for inflation, we see that monotonicity is always achieved and the non-rejection values take place when $\mathrm{d}$ is between 0.50 and 0.90 , thus including the non-rejections obtained with white noise disturbances. 
A Univariate Analysis of Unemployment and Inflation in Italy

\section{Table 1}

Testing the order of integration of unemployment and inflation in Italy with the tests of Robinson (1994a)

\begin{tabular}{|c|c|c|c|c|c|c|c|c|c|c|c|c|c|}
\hline$u_{t}$ & Series & $z_{t} / d_{o}$ & 0.50 & 0.60 & 0.70 & 0.80 & 0.90 & 1.00 & 1.10 & 1.20 & 1.30 & 1.40 & 1.50 \\
\hline & & - & 6.61 & 5.10 & 3.46 & 1.89 & 0.60 & -0.63 & -1.64 & -2.25 & -2.80 & -3.24 & -3.58 \\
\hline & $U_{t}$ & 1 & 9.39 & 5.26 & 2.23 & 0.36 & -0.80 & -1.79 & -2.48 & -3.02 & -3.44 & -3.77 & -4.04 \\
\hline White & & $(1, t)$ & 6.11 & 3.81 & 1.87 & 0.31 & -0.88 & -1.79 & .2 .49 & -3.03 & -3.45 & -3.78 & -4.04 \\
\hline \multirow[t]{5}{*}{ noise } & & - & 2.10 & -0.06 & -1.42 & -2.44 & -3.14 & -3.63 & -3.99 & -4.26 & -4.47 & -4.64 & -4.78 \\
\hline & $\nabla P_{t}$ & 1 & 1.28 & -0.48 & -1.74 & -2.61 & -3.23 & -3.67 & -4.00 & -4.26 & -4.46 & -4.63 & -4.77 \\
\hline & & $(1, t)$ & 0.96 & -0.61 & -1.78 & -2.63 & -3.23 & -3.67 & -4.00 & -4.26 & -4.46 & -4.63 & -4.77 \\
\hline & & $=$ & 8.10 & -11.20 & -17.04 & $4-12.45$ & $5-3.40$ & 0.49 & 1.28 & 0.82 & 0.14 & -0.51 & -1.08 \\
\hline & $U_{t}$ & 1 & -2.95 & -1.05 & 0.83 & 0.13 & -0.48 & -1.04 & -1.56 & -2.03 & -2.46 & -2.84 & -3.18 \\
\hline \multirow[t]{6}{*}{$\operatorname{AR}(1)$} & & $(1, t)$ & 0.21 & 1.18 & 1.76 & 0.17 & -0.44 & -1.04 & -1.58 & -2.06 & -2.49 & -2.86 & -3.18 \\
\hline & & - & 2.90 & 1.74 & 0.68 & -0.42 & -1.21 & -1.81 & -2.27 & -2.62 & -2.91 & -3.14 & -3.34 \\
\hline & $\nabla P_{t}$ & 1 & 2.05 & 0.97 & -0.02 & -0.86 & -1.60 & -2.00 & -2.40 & -2.71 & -2.97 & -3.18 & -3.37 \\
\hline & & $(1, t)$ & 1.69 & 0.77 & -0.11 & -0.89 & -1.61 & -2.00 & -2.39 & -2.70 & -2.96 & -3.17 & -3.34 \\
\hline & & - & -3.91 & -4.21 & -4.34 & -3.96 & -2.61 & 0.09 & 2.91 & 3.54 & 2.90 & 2.17 & 1.56 \\
\hline & $U_{t}$ & 1 & -1.10 & -0.28 & -0.04 & -0.10 & -0.20 & -0.31 & -0.44 & -0.59 & -0.76 & -0.94 & -1.13 \\
\hline \multirow[t]{6}{*}{$\operatorname{AR}(2)$} & & $(1, t)$ & -0.24 & -0.12 & -0.07 & -0.10 & -0.19 & -0.31 & -0.46 & -0.63 & -0.80 & -0.97 & -1.14 \\
\hline & & - & 0.43 & 0.30 & -0.03 & -0.30 & -1.62 & -1.99 & -2.02 & -2.08 & -2.12 & -2.19 & -2.36 \\
\hline & $\nabla P_{t}$ & 1 & 0.27 & 0.01 & -0.38 & -0.78 & -1.17 & -1.70 & -1.77 & -2.00 & -2.20 & -2.37 & -2.53 \\
\hline & & $(1, t)$ & 0.12 & 0.08 & -0.42 & -0.81 & -1.17 & -1.70 & -1.77 & -2.00 & -2.19 & -2.35 & -2.49 \\
\hline & & - & 2.24 & 1.76 & 1.00 & 0.48 & -0.08 & -0.70 & -1.21 & -1.78 & -2.02 & -2.34 & -2.68 \\
\hline & $U_{t}$ & 1 & 4.62 & 2.66 & 1.23 & 0.11 & -0.39 & -0.83 & -1.32 & -1.73 & -1.94 & -2.20 & -2.41 \\
\hline Bloomfield & & $(1, t)$ & 2.59 & 1.72 & 0.88 & 0.23 & -0.37 & -0.84 & -1.38 & -1.66 & -1.99 & -2.24 & -2.42 \\
\hline \multirow[t]{5}{*}{ (1) } & & - & 3.10 & 1.72 & 0.62 & -0.31 & -1.08 & -1.72 & -2.14 & -2.42 & -2.70 & -2.90 & -3.04 \\
\hline & $\nabla P_{t}$ & 1 & 2.08 & 0.06 & -0.04 & -0.88 & -1.44 & -1.93 & -2.25 & $-2,57$ & -2.71 & -2.89 & -3.12 \\
\hline & & $(1, t)$ & 1.73 & 0.67 & -0.16 & -0.78 & -1.40 & -1.93 & -2.24 & -2.56 & -2.69 & -2.94 & -3.03 \\
\hline & & - & 3.10 & 2.34 & 1.62 & -1.44 & -1.62 & -1.73 & -1.96 & -2.07 & -2.09 & -2.58 & -2.75 \\
\hline & $U_{t}$ & 1 & 3.05 & 2.61 & 1.21 & 0.90 & -0.10 & -0.71 & -2.14 & -2.36 & -2.68 & -2.78 & -2.81 \\
\hline \multirow{4}{*}{$\begin{array}{l}\text { Bloomfield } \\
\text { (2) }\end{array}$} & & $(1, t)$ & 2.71 & 1.86 & 0.98 & 0.82 & -0.07 & -0.44 & -2.21 & -2.45 & -2.79 & -2.86 & -2.87 \\
\hline & & - & 1.91 & 1.54 & -0.06 & -0.22 & -1.16 & -1.66 & -1.99 & -2.42 & -3.12 & -3.31 & -3.45 \\
\hline & $\nabla P_{t}$ & 1 & 1.81 & 0.14 & -0.06 & -1.04 & -1.68 & -1.71 & -2.31 & -2.50 & -2.76 & -3.02 & -3.44 \\
\hline & & $(1, t)$ & 1.13 & 1.07 & -0.24 & -1.11 & -1.70 & -1.96 & -2.07 & -2.48 & -3.12 & -3.32 & -3.61 \\
\hline
\end{tabular}

We computed the tests for the null hypothesis: $H_{0}: d=d_{0}$ in the model $y_{t}=\beta^{\prime} z_{t}+x_{t} ;(1-L)^{d} x_{t}=u_{t}$ : where $z_{t}=-$ means no regressors; $z_{t}=1$ means an intercept; and $z_{t}=(1, t)$ an intercept and a linear time trend. In bold: Non-rejection values of the null hypothesis at the $95 \%$ significant level in those cases where monotonicity in the value of the test with respect to $d$ was achieved. 
In order to solve the problem of potential misspecification in case of AR disturbances for unemployment, we use a nonparametric approach to model the $I(0) u_{t}$ which is due to Bloomfield (1973). In his model, the function $g$ appearing in (6) is given by

$$
g\left(\lambda_{j} ; \tau\right)=\exp \left(2 \sum_{l=0}^{k} \tau_{l} \cos \left(\lambda_{j} l\right)\right) .
$$

Like the stationary AR model, this has exponentially decaying autocorrelations. Formulae for Newton-type iteration for estimating the $\tau$ are very simple (involving no matrix inversion), updating formulae when $\mathrm{k}$ is increased are also simple, and we can replace $\hat{A}$ below (5) by the population quantity

$$
\sum_{l=k+1}^{\infty} l^{-2}=\frac{\pi^{2}}{6}-\sum_{l=1}^{k} l^{-2}
$$

which indeed is constant with respect to the $\tau_{l}$ (unlike what happens in the AR case). The results of the tests of Robinson (1994a) based on the Bloomfield (1973) exponential spectral model are displayed in the lower part of Table 1. We see that for unemployment, monotonicity is now always achieved and $H_{o}(4)$ cannot be rejected if $d_{o}$ is between 0.70 and 1.10 when $k=1$, and when it is between 0.70 and 1 with $k=2$. Thus, the unit root null hypothesis cannot be rejected in this context. Looking at the results for inflation, the values of $d_{o}$ where the null hypothesis cannot be rejected are between 0.60 and 0.90 , i.e., similarly to the case of AR disturbances.

We can summarize the results obtained across this table by saying that the unit root null hypothesis is always rejected in favour of smaller orders of integration in case of inflation. For unemployment, 
A Univariate Analysis of Unemployment and Inflation in Italy

the evidence against unit roots is not so conclusive though smaller values of $\mathrm{d}$ also seem plausible.

\section{Table 2}

Values of $d$ which produce the lowest statistic in absolute value $|\hat{r}|$ across $d_{o}$

\begin{tabular}{|c|c|c|c|c|c|}
\hline \multicolumn{3}{|c|}{ UNEMPLOYMENT } & \multicolumn{3}{|c|}{ INFLATION } \\
\hline$u_{t}$ & $z_{t}$ & $\begin{array}{l}\text { Value } \\
\text { of } \boldsymbol{d}\end{array}$ & $u_{t}$ & $z_{t}$ & $\begin{array}{l}\text { Value } \\
\text { of } \boldsymbol{d}\end{array}$ \\
\hline White & - & 0.94 & White & - & 0.60 \\
\hline \multirow[t]{2}{*}{ noise } & 1 & 0.82 & noise & 1 & 0.57 \\
\hline & $(1, t)^{\prime}$ & 0.82 & & $(1, t)^{\prime}$ & 0.56 \\
\hline \multirow[t]{3}{*}{$\operatorname{AR}(1)$} & - & - & $\operatorname{AR}(1)$ & - & 0.75 \\
\hline & 1 & - & & 1 & 0.70 \\
\hline & $(1, t)^{\prime}$ & - & & $(1, t)^{\prime}$ & 0.69 \\
\hline \multirow[t]{3}{*}{$\operatorname{AR}(2)$} & - & - & $\operatorname{AR}(2)$ & - & 0.69 \\
\hline & 1 & - & & 1 & 0.61 \\
\hline & $(1, t)^{\prime}$ & - & & $(1, t)^{\prime}$ & 0.61 \\
\hline Bloomfield & - & 0.89 & Bloomfield & - & 0.76 \\
\hline \multirow[t]{2}{*}{ (1) } & 1 & 0.84 & (1) & 1 & 0.70 \\
\hline & $(1, t)^{\prime}$ & 0.83 & & $(1, t)^{\prime}$ & 0.68 \\
\hline Bloomfield & - & 0.81 & Bloomfield & - & 0.70 \\
\hline \multirow[t]{2}{*}{ (2) } & 1 & 0.89 & (2) & 1 & 0.70 \\
\hline & $(1, t)^{\prime}$ & 0.88 & & $(1, t)^{\prime}$ & 0.69 \\
\hline
\end{tabular}

- means that monotonicity in the value of the test statistic across $d$ was not achieved. 
In order to get a more precise view about which may be the appropriate order of integration for each series, we display, in Table 2, the values of $d$ which produce the lowest $\hat{r}$ in absolute value across the different types of regressors and the different types of disturbances, using a grid of 0.01 . Starting with unemployment, we see that $d$ oscillates between 0.81 (in case of no regressors and Bloomfield (2) disturbances) and 0.94 (with no regressors and white noise $u_{t}$ ). For inflation, the values are much smaller, ranging between 0.56 (with a linear time trend and white noise $u_{t}$ ) and 0.76 (with no regressors and Bloomfield (1) ut). Thus, it seems clear that both series are nonstationary but mean reverting and that the degree of persistence is higher for unemployment than for the inflation rate.

In view of all these results it seems that the orders of integration in both series are smaller than one, especially in case of inflation. However, it also appears that these orders of integration substantially vary depending on how we specify the $I(0)$ disturbances. Because of this, we have also performed a semiparametric procedure (Robinson, 1995a), which is robust to the different types of disturbances, and that we are now to describe.

The Quasi Maximum Likelihood Estimate (QMLE) of Robinson (1995a) is basically a 'Whittle estimate' in the frequency domain, considering a band of frequencies that degenerates to zero. The estimate is implicitly defined by:

$$
\hat{d}=\arg \min _{d}\left(\log \overline{C(d)}-2 d \frac{1}{m} \sum_{j=1}^{m} \log \lambda_{j}\right)
$$


A Univariate Analysis of Unemployment and Inflation in Italy

$$
\overline{C(d)}=\frac{1}{m} \sum_{j=1}^{m} I\left(\lambda_{j}\right) \lambda_{j}^{2 d}, \quad \lambda_{j}=\frac{2 \pi j}{T}, \quad \frac{m}{T} \rightarrow 0
$$

where $I\left(\lambda_{j}\right)$ is the periodogram of the raw time series and $d \in$ $(-0.5,0.5){ }^{6}$ Under finiteness of the fourth moment and other mild conditions, Robinson (1995a) proved that:

$$
\sqrt{m}\left(\hat{d}-d_{o}\right) \rightarrow_{d} N(0,1 / 4) \text { as } T \rightarrow \infty,
$$

where $d_{o}$ is the true value of $\mathrm{d}$ and with the only additional requirement that $m \rightarrow \infty$ slower than T. Robinson (1995a) proposes that $\mathrm{m}$ should be smaller than $\mathrm{T} / 2$. A multivariate extension of this estimation procedure can be found in Lobato (1999). There also exist other semiparametric procedures for estimating the fractional differencing parameter, for example, the log-periodogram regression estimate (LPE), initially proposed by Geweke and Porter-Hudak (1983) and modified later by Künsch (1986) and Robinson (1995b) and the averaged periodogram estimate (APE) of Robinson (1994b). However, in this article, we have decided to use the QMLE first, because of its computational simplicity. Note that using the QMLE, we do not need to employ any additional user-chosen numbers in the estimation (as is the case with the LPE and the APE). Also, we do not have to assume Gaussianity in order to obtain an asymptotic normal distribution, the QMLE being more efficient than the LPE.

${ }^{6}$ Velasco $(1999 \mathrm{a}, \mathrm{b})$ has recently showed that the fractionally differencing parameter can also be consistently semiparametrically estimated in nonstationary contexts by means of tapering. 
Luis A. Gil-Alana

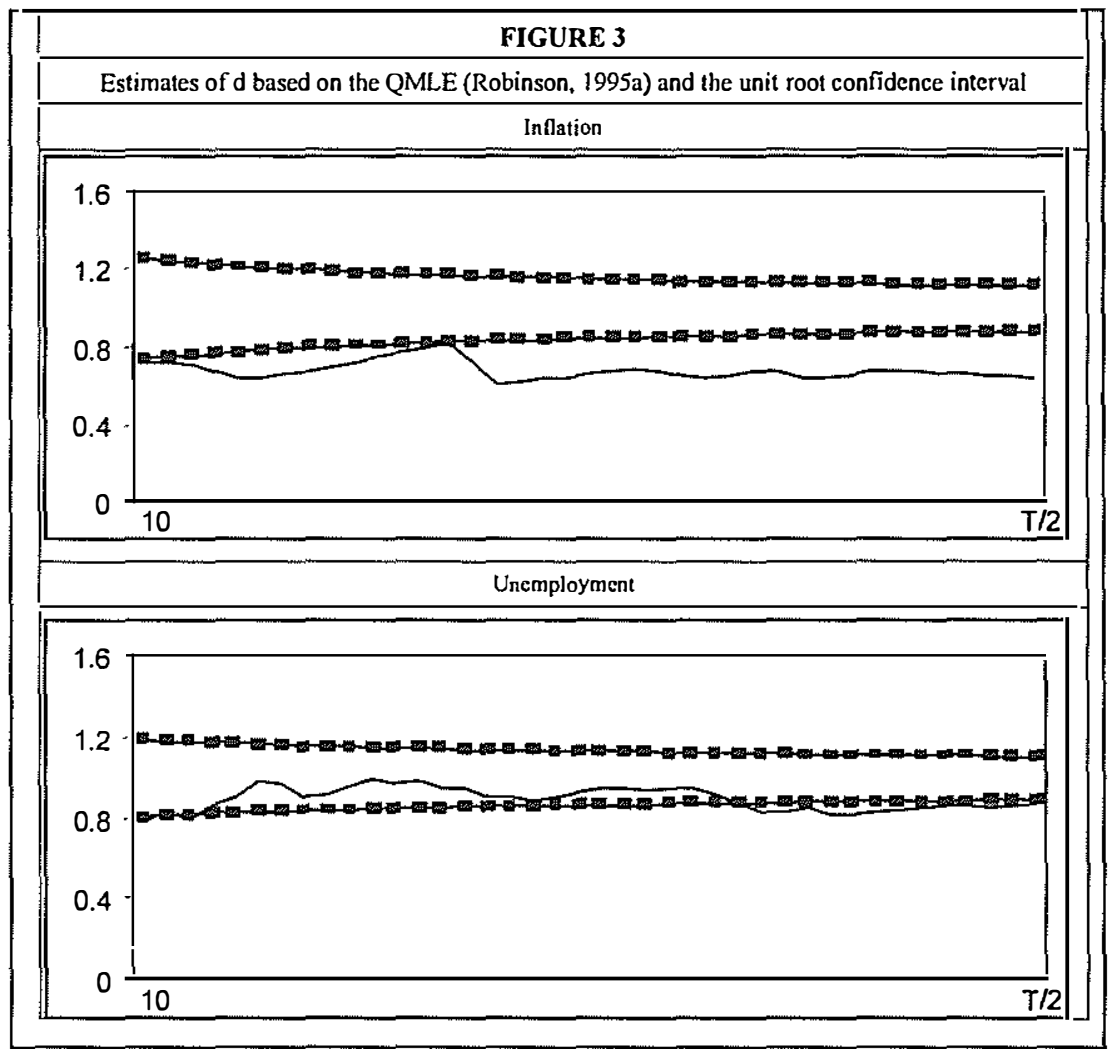

The horizontal axis corresponds to the bandwidth parameter number $m$ while the vertical one refers to the estimate of $d$ based on the QMLE of Robinson (1995a).

Figure 3 reports the results based on the QMLE of Robinson (1995a), i.e., $\hat{d}$ given by (11) for a range of values of $m$ from 10 to $\mathrm{T} / 2 .^{7}$ The figure also shows the confidence intervals corresponding to the unit root case. Starting with inflation, we observe that for practically all values of $m$, the estimates are below the unit root interval, with the values of $d$ oscillating around 0.6. However, for

${ }^{7}$ In order to assure stationarity, the estimates were based on the first differenced data, then adding one to the estimated values of $d$ to get the proper orders of integration. 
unemployment, the unit root null hypothesis cannot be rejected in some cases, and although the estimates are close to the lower bound of the confidence interval, many values are within such interval. The estimates for this series oscillate around 0.8. Thus, the results based on the semiparametric procedure are completely in line with those reported above in favour of mean reversion for both series and higher orders of integration for unemployment than for inflation.

Finally, and following Marcelino and Mizon (2001), we divide the sample into two subsamples corresponding to the time periods 1970-1979 and 1980-1994. They choose this period in view of the political and economic changes that occurred in that year which make the data have different characteristics pre- and post- 1980. In that paper, they still argue that both series in both subsamples may be well characterized in terms of unit roots.

Table 3

Values of $d$ which produce the lowest statistic $|\hat{r}|$ across $\boldsymbol{d}_{\circ}$ TIME PERIOD: 1970 - 1979

\begin{tabular}{lcclcc}
\hline \multicolumn{5}{c}{ UNEMPLOYMENT } & \multicolumn{3}{c}{ INFLATION } \\
\hline$u_{t}$ & $z_{t}$ & $\begin{array}{c}\text { Value } \\
\text { of } d\end{array}$ & $u_{t}$ & $z_{t}$ & $\begin{array}{c}\text { Value } \\
\text { of } \boldsymbol{d}\end{array}$ \\
\hline White & - & 0.86 & White & - & 0.37 \\
noise & 1 & 0.78 & noise & 1 & 0.42 \\
& $(1, t)^{\prime}$ & 0.75 & & $(1, t)^{\prime}$ & 0.41 \\
\hline AR(1) & - & - & AR(1) & - & - \\
& 1 & - & & 1 & - \\
\hline AR(2) & $(1, t)^{\prime}$ & - & & $(1, t)^{\prime}$ & - \\
\hline Bloomfield & - & - & AR(2) & - & - \\
$(1)$ & 1 & - & & 1 & - \\
& $(1, t)^{\prime}$ & - & & $(1, t)^{\prime}$ & 0.17 \\
\hline Bloomfield & - & 0.75 & Bloomfield & - & 0.30 \\
$(2)$ & $(1, t)^{\prime}$ & 0.55 & & 1 & 0.40 \\
& - & 0.77 & Bloomfield & - & 0.41 \\
\hline
\end{tabular}

- means that monotonicity in the value of the test statistic across $d$ was not achieved. 
Table 4

Values of $d$ which produce the lowest statistic $|\hat{r}|$ across $d_{o}$ TIME PERIOD: 1980 - 1994

\begin{tabular}{lcclcc}
\hline & UNEMPLOYMENT & & \multicolumn{2}{c}{ INFLATION } & \\
\hline$u_{t}$ & $z_{t}$ & $\begin{array}{c}\text { Value } \\
\text { of } d\end{array}$ & $u_{t}$ & $z_{t}$ & $\begin{array}{c}\text { Value } \\
\text { of } \boldsymbol{d}\end{array}$ \\
\hline White & - & 0.93 & White & - & 0.63 \\
noise & 1 & 0.85 & noise & 1 & 0.44 \\
& $(1, t)^{\prime}$ & 0.86 & & $(1, t)^{\prime}$ & 0.44 \\
\hline AR(1) & - & - & AR(1) & - & - \\
& 1 & - & & 1 & 0.51 \\
& $(1, t)^{\prime}$ & - & & $(1, t)^{\prime}$ & 0.55 \\
AR(2) & - & - & AR(2) & - & - \\
& 1 & - & & 1 & 0.38 \\
\hline Bloomfield & $(1, t)^{\prime}$ & - & & $(1, t)^{\prime}$ & 0.42 \\
$(1)$ & - & 0.87 & Bloomfield & - & 0.72 \\
& 1 & 0.71 & $(1)$ & 1 & 0.51 \\
\hline Bloomfield & $(1, t)^{\prime}$ & 0.82 & & $(1, t)^{\prime}$ & 0.59 \\
$(2)$ & - & 0.88 & Bloomfield & - & 0.67 \\
& 1 & 0.81 & $(2)$ & 1 & 0.54 \\
\hline
\end{tabular}

- means that monotonicity in the value of the test statistic across $d$ was not achieved.

Tables 3 and 4 summarize the values of $d$ for each series in both subsamples, according to the same criterion as in Table 2. Several features are observed in these two tables: first, the values of $d$ are higher in both subsamples for unemployment than for inflation, corroborating the fact that unemployment is more persistent than inflation. Also, the orders of integration are higher in both series during the period 1980-1994, suggesting that the level of association between the observations has substantially increased over the sample period. Thus, for unemployment, d oscillates between 0.55 and 0.86 during the first subsample and it ranges between 0.71 and 0.93 during the second one. Similarly for inflation, $\mathrm{d}$ is between 0.17 and 
0.42 for the time period 1970-1979 and ranges between 0.38 and 0.72 for 1980-1994.

One advantage of Robinson's (1994a) tests is that they permit us to incorporate deterministic breaks in the model, with no effect on its standard null limit distribution. Note that $z_{t}$ in (3) contains deterministic regressors and thus, we can include dummy variables to take into account the breaks. We can test $H_{o}(4)$ in (1) and (3), with $z_{t}=\left(1, S B\left(T_{b}\right)_{t}\right)^{\prime}$, i.e.,

$$
y_{t}=\alpha+\beta S B\left(T_{b}\right)_{t}+x_{t} ; \quad(1-L)^{d} x_{t}=u_{t}
$$

where $S B\left(T_{b}\right)_{t}$ is a dummy variable for the break that may adopt the forms of a shift dummy, (i.e., $S B\left(T_{b}\right)_{t}=D U\left(T_{b}\right)_{t}=1 I\left(t>T_{b}\right)$ ), a slope dummy (i.e., $S B\left(T_{b}\right)_{t}=D L\left(T_{b}\right)_{t}=t I\left(t>T_{b}\right)$ ), or a combination of both. Clearly, the test statistic will still remain with the same null $N(0,1)$ limit distribution, which holds across a broad class of exogenous regressors. As mentioned just above, this is another distinguishing feature of the tests, compared with other unit-root tests based on AR alternatives, where the null limit distribution can vary with features of the regressors. (See, e.g., Schmidt and Phillips, 1992). This is motivated by the work of Perron $(1988,1989)$ for the case of unit-root tests. In these papers, he found that the 1929 crash and the 1973 oil price shock were a cause of non-rejection of the unit root, and that when these were taken into account, deterministic models were preferable. This question was also examined by Christiano (1992), Demery and Duck (1992), Krol (1992), Mills (1994), Bai and Perron (1998), etc., some of these authors arguing that the date of the break should be taken as unknown. In the context of fractional roots, Diebold and Inoue (1999) provide both theoretical and Monte Carlo evidence that structural breaks-based models and long memory processes are easily confused. Similarly, Granger and Hyung (1999) also developed a theory relating both types of models. 


\section{Table 5}

Confidence intervals of the non-rejection values of $d$ in the context of structural breaks

\begin{tabular}{lcc}
\hline$u_{t} /$ Series & UNEMPLOYMENT & INFLATION \\
\hline White noise & {$[0.78-1.00]$} & {$[0.39-0.63]$} \\
\hline AR $(1)$ & {$[0.86-1.13]$} & {$[0.25-0.82]$} \\
\hline AR $(2)$ & {$[0.88-1.17]$} & {$[0.38-0.95]$} \\
\hline Bloomfield(1) & {$[0.73-1.11]$} & {$[0.32-0.71]$} \\
\hline Bloomfield $(2)$ & {$[0.70-1.14]$} & {$[0.34-0.66]$} \\
\hline
\end{tabular}

The confidence interval refers to the values of $d$ where $H_{0}$ cannot be rejected at the $95 \%$ significance level. We test: $H_{o}: d=d_{o}$ in the model $y_{t}=\alpha+\beta^{\prime} S B\left(T_{b}\right)+x_{t} ;(1-$ $L)^{d} x_{t}=u_{t}$, where $S B\left(T_{b}\right)=t I\left(t>T_{b}\right), T_{b}=1980$.

Table 5 displays the confidence intervals of those values of $\mathrm{d}$ where $H_{o}$ (4) cannot be rejected in (12) and (9) using a slope dummy and $T_{b}=1980$. In fact, the inclusion of a shift dummy was found insignificant in all models for practically all values of $d$. Note that the tests are based on the null differenced model, which is supposed to be $I(0)$ and thus, standard $t$-tests apply. We see in this table that for inflation, all intervals exclude the unit roots, the values ranging from $0.25\left(\mathrm{AR}(1)\right.$ disturbances) to 0.95 (with $\left.\mathrm{AR}(2) u_{t}\right)$. Thus, even including a break, the results strongly support the hypothesis of long memory and mean reversion. However, for unemployment, the unit root cannot be rejected for any type of disturbances if they are autocorrelated and, if they are white noise, the interval for the non-rejection values becomes $[0.78,0.99]$.

\section{Concluding Remarks.}

In this article we have examined the univariate behaviour of the unemployment and inflation rates in Italy by means of fractionally 
integrated techniques. We used the same dataset as in Marcelino and Mizon (2001), i.e., seasonally (quarterly) adjusted data for the time period 1970-1994. For this purpose, we have used a version of the tests of Robinson (1994a) that permits us to test unit and fractional roots in raw time series. Surprisingly, and contrary to Marcelino and Mizon (2001), the results strongly reject the unit root null hypothesis in case of the inflation rate, while for unemployment this hypothesis is also sometimes rejected. The reason for the nonrejection of the unit roots in Marcelino and Mizon (2001) may be due in large part to the fact that most commonly unit-root tests have very low power and extreme size distortions in case of autocorrelated disturbances and in that respect, the tests of Robinson (1994) outperform them in a number of cases. Moreover, performing a semiparametric procedure of Robinson (QMLE, 1995a), which is robust to the different types of disturbances, the results support the view that inflation is $I(d)$ with $d<1$, while the unit root cannot be rejected for unemployment. Similar conclusions are obtained with the tests of Robinson (1994a) if a slope dummy is included in the regression model to take into account a break in 1980 . The results obtained in this paper have strong implications in terms of economic policy. Thus, if both variables are $I(d)$ with $d<1$, that means that they are mean reverting, with the effect of the shocks dying away in the long run as opposed to the unit root case with shocks persisting forever. Furthermore, the inference about cointegration (at least in its classical sense) implicitly assumes that both variables are $I(1)$ so in case of building a cointegrating system, a different dataset for these variables should be perhaps employed. In fact, in a recent paper, Gonzalo and Lee (2000) showed that if the individual series are fractionally integrated, the performance of Johansen's (1988)-type tests for cointegration tends to produce too much spurious cointegrating relationships, while Engle and Granger's (1987)-type tests seem to be more robust. This latter approach has been used in Gil- 
Alana (2003). However, a necessary condition for the existence of (fractional) cointegration, at least in a bivariate system, is that both individual series must have the same degree of integration, which is not the case in the present work.

In any case, the key question is to determine whether unemployment and inflation are $\mathrm{I}(1)$ or $I(d)$ with $d<1$. It seems clear that the results in this paper strongly support the latter case though this may be due to the type of data under analysis (quarterly seasonally adjusted). How the presence of periodicities or anomalous values in the time series under study may affect to the conclusions obtained here will be examined in future papers. On the other hand, we have shown that the order of integration of the series can substantially vary depending on how we specify the $I(0)$ disturbances and, though similar results were obtained with the QMLE of Robinson (1995a), the estimation of the fractional differencing parameter, using perhaps other techniques (e.g., Robinson, 1994b, 1995b, Tanaka, 1999; Dolado et al., 2002) or the determination of a specific model through information criteria might shed further light on this matter. Multivariate versions of the tests of Robinson (1994a) are being developed and this would lead to an alternative study of cointegration, examining the long run relationship between inflation and unemployment. However, the literature on fractional cointegration is still in its infancy and much more theoretical work needs to be examined before proceeding to a particular empirical work in this area.

Submitted in January 2003. Revised in September 2003.

\section{References}

Adenstedt, R. K. 1974. "On large-sample estimation for the mean of a stationary random sequence", Annals of Statistics, 2, 259-272. 
A Univariate Analysis of Unemployment and Inflation in Italy

Bai, J. \& P. Perron 1998. "Estimating and testing linear models with multiple structural changes", Econometrica, 66, 44-78.

Ball, L. \& S. G. Cecchetti 1990. "Inflation and uncertainty at short and long horizons", Brooking Papers on Economic Activity, 215254.

Barsky, R. B. 1987. "The Fisher hypothesis and the forecastability and persistence of inflation", Journal of Monetary Economics, 19, 3-24.

Bhargava, A. 1986. "On the theory of testing for unit roots in observed time series", Review of Economic Studies, 53, 369-384.

Bloomfield, P. 1973. "An exponential model in the spectrum of a scalar time series". Biometrika, 60, 27-226.

Carruth, A., M. Hooker \& A. Oswald 1998. "Unemployment equilibria and input prices: Theory and evidence for the United States", The Review of Economics and Statistics, 80, 621-628.

Chambers, M. 1998. "Long memory and aggregation in macroeconomic time series", International Economic Review, 39, 10531072.

Christiano, L. J. 1992. "Searching for a break in the GNP". Journal of Business Economics and Statistics, 10, 237-250.

Croczek-Georges, R. \& B. B. Mandelbrot 1995. "A class of micropulses and antipersistent fractional Brownian motion", Stochastic Processes and Their Applications, 60, 1-18.

Demery, D. \& N. W. Duck 1992. "Are economic fluctuations really persistent? A reinterpretation of some international evidence". The Economic Journal, 102, 1094-1101.

Dickey, D. A. \& W. A. Fuller 1979. "Distributions of the estimators for autoregressive time series with a unit root", Journal of the American Statistical Association, 74, 427-431. 
Diebold, F. X. \& A. Inoue 2001. "Long memory and regime switching", Journal of Econometrics, 105, 131-159.

Dolado, J. J., J. Gonzalo \& L. Mayoral 2002. "A fractional DickeyFuller test", Econometrica, 70, 1963-2006.

Engle, R. F. \& C. W. J. Granger 1987. "Cointegration and error correction: Representation, estimation and testing", Econometrica, 55, 251-276.

Geweke, J. \& S. Porter-Hudak 1983. "The estimation and application of long memory time series models", Journal of Time Series Analysis, 4, 221-238.

Gil-Alana, L. A. 1999. "Testing fractional integration with monthly data", Economic Modelling, 16, 613-629.

Gil-Alana, L. A. 2000a. "Mean reversion in the real exchange rates", Economics Letters, 69, 285-288.

Gil-Alana, L. A. 2000b. "Evaluation of Robinson's (1994) tests in finite samples", Journal of Statistical Computation and Simulation, 68, 39-64.

Gil-Alana, L. A. 2001. "Testing of stochastic cycles in macroeconomic time series", Journal of Time Series Analysis, 22, 411-430.

Gil-Alana, L. A. 2003. "Testing of fractional cointegration in macroeconomic time series", Oxford Bulletin of Economics and Statistics, 65, 517-529.

Gil-Alana, L. A. \& P. M. Robinson 1997. "Testing of unit roots and other nonstationary hypotheses in macroeconomic time series", Journal of Econometrics, 80, 241-268.

Gil-Alana, L. A. \& P. M. Robinson 2001. "Testing seasonal fractional integration in the UK and Japanese consumption and income series", Journal of Applied Econometrics, 16, 95-114.

Gonzalo, J. \& T-H. Lee 2000. "On the robustness of cointegration 
A Univariate Analysis of Unemployment and Inflation in Italy

tests when series are fractionally integrated", Journal of Applied Statistics, 27, 821-827.

Granger, C. W. J. 1980. "Long memory relationships and the aggregation of dynamic models", Journal of Econometrics, 14, 227238.

Granger, C. W. J. 1981. "Some properties of time series data and their use in econometric model specification", Journal of Econometrics, 16, 121-130.

Granger, C. W. J. \& R. Joyeux 1980. "An introduction to long memory time series and fractionally differencing", Journal of Time Series Analysis, 1, 15-29.

Granger, C. W. J. \& J. Hyung 1999. "Occasional structural breaks and long memory", Discussion Paper, 99-14, University of California, San Diego.

Hosking, J. R. M. 1981. "Modelling persistence in hydrological time series using fractional differencing", Water Resources Research, 20, 1898-1908.

Johansen, S. 1988. "Statistical analysis of cointegrating vectors", Journal of Economics Dynamics and Control, 12, 231-254.

Krol, R. 1992. "Trends, random walks and persistence: an empirical study of disaggregated U.S. industrial production". Review of Economics and Statistics, 74, 154-166.

Kïnsch, H. 1986. "Discrimination between monotonic trends and long-range dependence", Journal of Applied Probability, 23, 1025-1030.

Kwiatkowski, D., P. C. B. Phillips, P. Schmidt, \& Y. Shin 1992. "Testing the null hypothesis of stationarity against the alternative of a unit root", Journal of Econometrics, 54, 159-178.

Lippi, M. \& P. Zaffaroni 1999. "Contemporaneous aggregation 
of linear dynamic models in large economies", Manuscript, Research Department, Bank of Italy.

Lobato, I., 1999. "A semiparametric two-step estimator for a multivariate long memory process", Journal of Econometrics, 73, 303-324.

Marcelino, M. \& G.E. Mizon 2001. "Small-system modelling of real wages, inflation, unemployment and output per capita in Italy 1970-1994", Journal of Applied Econometrics, 16, 359-370.

Marinucci, D. \& P. M. Robinson 1998. "Semiparametric frequency domain analysis of fractional cointegration", STICERD, London School of Economics, Discussion Paper Series EM/98/348.

Mills, T. C. 1994. "Infrequent permanent shocks and the unit root in quarterly U.K. output". Bulletin of Economic Research, 46, 91-94.

Parke, W. R. 1999. "What is fractional integration?" The Review of Economics and Statistics, 81, 632-638.

Perron, P. 1988. "Trends and random walks in macroeconomic time series", Journal of Economic Dynamics and Control, 12, 297332.

Perron, P. 1989. "The great crash, the oil price shock and the unit root hypothesis", Econometrica, 57, 1361-1401.

Phillips, P. C. B. \& P. Perron 1988. "Testing for a unit root in a time series regression", Biometrika, 75, 335-346.

Robinson, P. M. 1978. "Statistical inference for a random coefficient autoregressive model", Scandinavian Journal of Statistics, 5, 163-168.

Robinson, P. M. 1994a. "Efficient tests of nonstationary hypotheses", Journal of the American Statistical Association, 89, 14201437. 
A Univariate Analysis of Unemployment and Inflation in Italy

Robinson, P. M. 1994b. "Semiparametric analysis of long memory time series", Annals of Statistics, 22, 515-539.

Robinson, P. M. 1995a. "Gaussian semiparametric estimation of long range dependence", Annals of Statistics, 23, 1630-1661.

Robinson, P. M. 1995b. "Log-periodogram regression of time series with long range dependence", Annals of Statistics, 23, 10481072.

Rose, A. K. 1988. "Is the real interest rate stable?" Journal of Finance, 43, 1095-1112.

Schmidt, P. \& P. C. B. Phillips 1992. "LM tests for a unit root in the presence of deterministic trends", Oxford Bulletin of Economics and Statistics, 54, 257-287.

Tanaka, K. 1999. "The nonstationary fractional unit root", Econometric Theory, 15, 549-582.

Tanaka, K. 1999. "The nonstationary fractional unit root", Econometric Theory, 15, 549-582.

Taqqu, M. S. 1975. "Weak convergence to fractional motion and to the Rosenblatt process", Z. Wahrscheinlichkeitstheorie verw. Geb., 31, 287-302.

Taqqu, M. S., W. Willinger \& R. Sherman 1997. "Proof of a fundamental result in self-similar traffic modelling", Computer Communication Review, 27, 5-23.

Velasco, C. 1999a. "Nonstationary log-periodogram regression", Journal of Econometrics, 91, 299-323.

Velasco, C. 1999b. "Gaussian semiparametric estimation of nonstationary time series", Journal of Time Series Analysis, 20, 87-127.

Wallis, K. 1987. "Time series analysis of bounded economic variables", Journal of Time Series Analysis, 8, 115-123. 